\title{
Correction to: Ecological distribution conflicts as forces for sustainability: an overview and conceptual framework
}

\author{
Arnim Scheidel $^{1,2}\left(\mathbb{D} \cdot\right.$ Leah $_{\text {Temper }}{ }^{2} \cdot$ Federico Demaria $^{2} \cdot$ Joan Martínez-Alier $^{2}$
}

Published online: 22 December 2017

(c) The Author(s) 2017

\section{Correction to: Sustainability Science https://doi.org/10.1007/s11625-017-0519-0}

The article Ecological distribution conflicts as forces for sustainability: an overview and conceptual framework, written by Arnim Scheidel, Leah Temper, Federico Demaria and Joan Martínez-Alier was originally published electronically on the publisher's internet portal (currently SpringerLink) on 13 December 2017 without open access.

With the author(s)' decision to opt for Open Choice the copyright of the article changed on 13 December 2017 to $($ )
The Author(s) 2017 and the article is forthwith distributed under the terms of the Creative Commons Attribution 4.0 International License (http://creativecommons.org/licenses/ by/4.0/), which permits use, duplication, adaptation, distribution and reproduction in any medium or format, as long as you give appropriate credit to the original author(s) and the source, provide a link to the Creative Commons license and indicate if changes were made.

The original article was corrected.

The original article can be found online at https://doi.org/10.1007/ s11625-017-0519-0.

Arnim Scheidel

arnim.scheidel@gmail.com

1 International Institute of Social Studies (ISS), Erasmus University Rotterdam (EUR), The Hague, The Netherlands

2 Institute of Environmental Science and Technology (ICTA), Universitat Autónoma de Barcelona (UAB), Barcelona, Spain 